\title{
Questões econômicas e solidárias e sua influência na sobrevivência de empreendimentos econômicos solidários na região sul do Brasil
}

\author{
Economic and solidarity issues and their influence on the survival of solidarity \\ economic enterprises in the southern region of Brazil
}

\section{Daniel Nogueira Silval', Sylvio Antonio Kappes"}

\begin{abstract}
Resumo
Ao analisar os dados do Primeiro Mapeamento Nacional da Economia Solidária, Gaiger (2007) criou os Coeficientes de Alto e Baixo Solidarismo e Empreendedorismo, com o objetivo de verificar a relação entre as dimensões solidária e empreendedora dos Empreendimentos Econômicos Solidários (EES). O presente artigo tem por objetivo utilizar tais coeficientes como variáveis explicativas para a sobrevivência dos EES entre o Primeiro e o Segundo Mapeamento. Para tanto, utiliza-se um modelo Logit. Verifica-se que a capacidade de obtenção de crédito e das decisões tomadas pelo conjunto dos sócios atua no sentido de elevar a sobrevivência dos EES, enquanto a participação cotidiana na gestão do empreendimento, a incapacidade de pagar as despesas do ano, a inexistência de benefícios para os sócios trabalhadores e a ausência de atividades coletivas reduzem a probabilidade de que tal sobrevivência ocorra.
\end{abstract}

Palavras-chave: Economia Solidária; Economia Alternativa; Modelos Logit

\section{Abstract}

Gaiger (2007) developed the Coefficients of High and Low Solidarity and Entrepreneurship, in order to verify the relationship between the solidary and entrepreneurial dimensions of Solidarity Economy Enterprises (EES). The purpose of this article is to use such coefficients as explanatory variables for the survival of the ESS between the First and Second Mappings. For this, a Logit model is used. It is verified that the capacity to obtain credit and the decisions taken by all the partners acts to increase the survival of the ESS, while the daily participation in the management of the enterprise, the inability to pay the expenses of the year, the non-existence of benefits for working partners and the absence of collective activities reduce the likelihood of such survival occurring.

Keywords: Solidary Economics; Alternative Economics; Logit models

\footnotetext{
I Universidade Federal do Sul e Sudeste do Pará ,Professor de Economia - ddaniel.ns@gmail.com

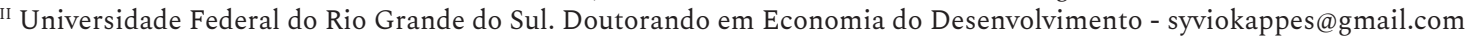




\section{Introdução}

O termo "Economia Solidária” é utilizado por diversos autores em perspectivas das mais amplas (SINGER, 2003). Segundo Laville e Gaiger (2009, p. 162), suas diversas acepções "giram ao redor da ideia de solidariedade, em contraste com o individualismo utilitarista que caracteriza o comportamento econômico predominante nas sociedades de mercado". Para esses autores, o termo surgiu na década de 1990, quando houve uma emergência de atividades econômicas baseadas segundo princípios de cooperação, autonomia e gestão democrática, assumindo os mais variados formatos, como cooperativas de produção e comercialização, clubes de troca, sistemas de comércio justo, associações de mulheres etc. Em comum, todos zelam pela primazia da solidariedade sobre o interesse individual e o ganho material.

Esses novos tipos de organização econômica foram objeto de estudo de diversos intelectuais, sendo o principal deles Paul Singer (CATTANI, 2003), que elaboraram conceitos capazes de abarcar teoricamente esse novo formato de célula produtiva. Gaiger (2009, p. 182) enumera alguns desses conceitos. Um deles é o de "empresas de economia popular”, criado por Nyssens (1996), que se refere às formas híbridas entre práticas não mercantis e integradas ao mercado. As "empresas de economia solidária”, conforme o conceito de Verano (2001), são aquelas onde se desenvolvem diversos tipos de atividade econômica, baseadas na propriedade comum dos meios de produção e na gestão coletiva. As "empresas alternativas", conceito de Razeto (1990), são aquelas que seguem os princípios de inserção de pessoas socialmente desfavorecidas, evolução pessoal dos trabalhadores, preservação do meio ambiente e envolvimento com os movimentos coletivos. Finalmente, as “organizações produtivas da economia social” são aquelas onde se superam as relações mercantis, ingressando em interações, cujo objetivo é a satisfação das necessidades (CARPI, 1997).

Gaiger (2009, p. 183), enfim, caracteriza-os como Empreendimentos Econômicos Solidários (EES), um conceito que "compreende as diversas modalidades de organização econômica, originadas da livre associação de trabalhadores, nas quais a cooperação funciona como esteio de sua eficiência e viabilidade”. Esses empreendimentos aparecem nas mais variadas atividades econômicas, desde a produção de bens, prestação de serviços e comercialização até os clubes de troca e cooperativas de crédito, organizando-se em formas também diversas, como grupos informais, associações e cooperativas. No Brasil, quando se fala em formas alternativas de organizações econômicas contrapostas ao capitalismo dominante, usa-se esse termo.

Os Empreendimentos Econômicos Solidários (EES) possuem uma racionalidade produtiva distinta, cujo eixo de sustentação passa a ser o solidarismo ao invés do capital (SCHIMDT, 2010). Sua razão de ser consiste no atendimento das necessidades materiais e não monetárias de seus membros, como o reconhecimento, a inserção social e a autonomia (GAIGER, 2009). Além disso, são sociedades de pessoas - e não de capitais - que possuem características singulares, como a indivisibilidade das figuras do trabalhador e do proprietário, a gestão democrática e o engajamento em movimentos sociais e redes (GAIGER, 2007).

Outro aspecto dessa racionalidade específica dos EES refere-se ao conceito de eficiência, que assume um caráter divergente ao das empresas capitalistas convencionais e está implícito na própria ideia de Economia Solidária. No âmbito da economia de mercado contemporânea, a eficiência é entendida, na maioria dos casos, apenas como a satisfação de critérios de maximização da relação custo/benefício, uma vez que esta influi decisivamente na lucratividade dos negócios. A Economia Solidária, por sua vez, adota um critério de eficiência que persegue também objetivos socioculturais e ético-morais, repousados em sua racionalidade específica determinada pela junção de três pontos-chave: a apropriação coletiva dos meios de produção, a autogestão e o trabalho associado (GAIGER, 2009).

No entanto, o enfrentamento dessas duas lógicas opostas em termos de eficiência cria desafios consideráveis à parte menos representativa - ou seja, à Economia Solidária (SINGER, 2008). O contexto atual da economia de mercado impõe requisitos cada vez mais exigentes quanto às competências, capacidades de inovação e desempenho competitivo, criando dificuldades tanto às empresas capitalistas quanto às formas alternativas de produção (GAIGER, 2007). O desafio da Economia Solidária é, portanto, o de conjugar duas formas de eficiência: a sua própria, como explicado acima, e a de mercado, fundamental para a continuidade dos EES em termos econômicos, adquirindo assim um caráter de eficiência sistêmica (GAIGER, 2004). Tal entrelaçamento de questões solidárias e empreendedoras foi o que motivou a criação dos coeficientes de solidarismo e empreendedorismo.

Para analisar os resultados do Primeiro Mapeamento Nacional da Economia Solidária, Gaiger (2007) criou os coeficientes de Solidarismo e Empreendedorismo, cada um subdividido em dois componentes: o alto, relacionado às características positivas, seja de empreendedorismo ou solidarismo; e o baixo, que se refere às características negativas destes conceitos. Kuyven e Kappes (2013) utilizaram-se desses coeficientes para analisar os fatores que influenciam a sobrevivência dos EES ao longo do tempo. O objetivo do presente trabalho é analisar os determinantes da sobrevivência dos EES com base em um modelo Logit (BALTAGI, 2002; GUJARATI, 1999) que incorpore estes coeficientes de Solidarismo e Empreendedorismo.

O trabalho possui, além desta introdução, outras quatro seções. A segunda versa sobre os Mapeamentos Nacionais 
da Economia Solidária, a terceira sobre os Coeficientes de Solidarismo e Empreendedorismo, a quarta apresenta o modelo, e a quinta traz as conclusões.

\section{Os mapeamentos nacionais da economia solidária}

Nos últimos anos, a Economia Solidária tem se articulado em vários fóruns locais e regionais, resultando na criação do Fórum Brasileiro de Economia Solidária (GAIGER, 2009). Em 2003, o Governo Federal criou a Secretaria Nacional de Economia Solidária (SENAES), ligada ao então Ministério do Trabalho e Emprego (MTE). Dentre as atribuições da SENAES está a criação do Sistema de Informações em Economia Solidária (SIES), cujos objetivos são: constituição de uma base nacional de informações em economia solidária com identificação e caracterização de Empreendimentos Econômicos Solidários e de Entidades de Apoio, Assessoria e Fomento à Economia Solidária; fortalecimento e integração de EES em redes e arranjos produtivos e organizativos, através de catálogos de produtos e serviços a fim de facilitar processos de comercialização; contribuir para a visibilidade da economia solidária; subsidiar processos públicos de reconhecimento da economia solidária; subsidiar a formulação de políticas públicas; subsidiar a elaboração de marco jurídico adequado à economia solidária; facilitar o desenvolvimento de estudos e pesquisas em economia solidária.

Com o propósito de atender aos objetivos citados acima, uma das ações que foram tomadas foi a execução de dois mapeamentos nacionais da Economia Solidária (ES). O primeiro foi realizado em 2005, com uma etapa complementar em 2007, identificando 21.859 EES em 2.934 municípios do Brasil (o que corresponde a 52\% dos municípios brasileiros). O Segundo Mapeamento foi executado entre 2011 e 2013, catalogando 19.708 empreendimentos.

Para incluir um empreendimento qualquer nos mapeamentos, o SIES adota alguns critérios que determinam se uma determinada organização econômica é um EES ou não. Nesse sentido, são considerados EES aquelas organizações que possuem as seguintes características:

- Coletivas - serão consideradas as organizações suprafamiliares, singulares e complexas, tais como: associações, cooperativas, empresas autogestionada, grupos de produção, clubes de trocas, redes etc.;

- Cujos participantes ou sócios (as) são trabalhadores (as) dos meios urbano e rural que exercem coletivamente a gestão das atividades, assim como a alocação dos resultados;

- Permanentes, incluindo os empreendimentos que estão em funcionamento e aqueles que estão em processo de implantação, com o grupo de participantes constituído e as atividades econômicas definidas;

- Que disponham ou não de registro legal, prevalecendo a existência real, e

- Que realizam atividades econômicas de produção de bens, de prestação de serviços, de fundos de crédito (cooperativas de crédito e os fundos rotativos populares), de comercialização (compra, venda e troca de insumos, produtos e serviços) e de consumo solidário.

Os dados levantados pelos dois mapeamentos apontam para diversos desafios enfrentados pelos empreendimentos econômicos solidários. Como apontado em uma pesquisa do Instituto de Pesquisa e Economia Aplicada (IPEA), a economia solidária é um importante instrumento de combate à pobreza e de sustento para muitas famílias (SCHIOCHET, SILVA, 2013). Contudo, é necessário avançar na consolidação desses empreendimentos, o que exige, entre outros elementos, uma maior eficiência econômica (FRANÇA FILHO, 2002). Segundo Singer (2003), muitos empreendimentos encontram-se diante do impasse entre serem, por um lado, mais eficientes econômicos, e do outro, garantirem o cumprimento dos princípios que norteiam a economia solidária. Alcançar o equilíbrio entre esses dois objetivos é um dos grandes desafios para a Economia Solidária. Diante desse cenário e com base nos dois mapeamentos que os trabalhos de Gaiger (2007) e Kuyven e Kappes (2013) foram realizados.

\section{Os coeficientes de solidarismo e empreendedorismo}

A presente seção tem como objetivo sumariar as discussões de Gaiger (2007) e Kuyven e Kappes (2013), de modo a levantar aspectos relevantes para a construção do modelo Logit que foi utilizado neste trabalho. 


\section{A proposta de Gaiger}

Gaiger (2007), ao analisar os resultados do Primeiro Mapeamento, avaliou os aspectos negativos e positivos das duas dimensões de interesse, ou seja, do Solidarismo e do Empreendedorismo. Em um primeiro momento, criou os coeficientes de baixo Solidarismo e baixo Empreendedorismo, selecionando variáveis do questionário do mapeamento que apontassem para uma inadequação à lógica solidária ou para uma baixa capacidade empreendedora. Assim, quanto maior a pontuação, menos Solidário ou Empreendedor um EES será. Contudo, em seu artigo, Gaiger (2007) não apresenta de forma detalhada como foram construídos e quais são esses indicadores. Apenas em Kuyven e Kappes (2013) que eles são apresentados.

Segundo Kuyven e Kappes (2013), as variáveis que compõem o coeficiente de Baixo Solidarismo são:

i. Não indicou nenhuma forma de atividade coletiva;

ii. Inexistência de assembleia ou reunião do coletivo de sócios;

iii. Ausência de órgãos diretivos de natureza democrática;

iv. Inexistência de mecanismos de participação;

v. Existência de trabalhadores não sócios;

vi. Ausência de participação em rede ou fórum de articulação;

vii. Ausência de participação em movimentos sociais e populares;

viii. Ausência de realização ou participação em ação social ou comunitária;

ix. Inexistência de preocupação com a qualidade de vida dos consumidores.

Por outro lado, as variáveis que compõem o coeficiente de Baixo Empreendedorismo são definidas da seguinte forma:

i. Insumos, matérias-primas ou recursos iniciais doados;

ii. Sede ou equipamentos cedidos ou emprestados;

iii. Produção destinada unicamente ao autoconsumo;

iv. Despreparo para a prática de comercialização;

v. Não conseguiu pagar as despesas do ano;

vi. Não está conseguindo remunerar os sócios que trabalham no EES;

vii. Não existem benefícios para os sócios trabalhadores;

viii. Trabalhadores não sócios em caráter permanente na produção;

ix. Inexistência de tratamento de resíduos gerados pelo EES.

Para cada variável, o EES recebe uma pontuação de 0 ou 1, sendo a primeira no caso de não apresentar o aspecto citado, e 1 caso o apresente. Assim, a pontuação desses coeficientes vai de 0 a 9. Gaiger (2007) constatou que o desempenho global dos EES mostrou-se satisfatório no que tange a não possuírem propriedades ou exercerem práticas indicadoras da ausência de empreendedorismo ou de solidarismo: 93,7\% deles incidem no máximo em 6 indicadores, dos 18 utilizados, e apenas 0,5\% incidem em 9 indicadores ou mais.

Na sequência, Gaiger (2007) elabora os coeficientes de Alto Solidarismo e Alto Empreendedorismo, visando, desta vez, analisar as características positivas das dimensões analisadas. Esses coeficientes não são diametralmente 
opostos aos de baixo Solidarismo e Empreendedorismo, pois, como afirma o próprio autor:

Cada indicador relaciona-se a um conjunto de questões afins, consideradas simultaneamente ou alternativamente. Como os indicadores de alto desempenho não recaem nas mesmas variáveis utilizadas pelos indicadores de baixo desempenho, evita-se dividir tautologicamente os empreendimentos em dois polos dicotômicos, conforme tenham respondido sim ou não às questões. Por outro lado, essa técnica nem sempre permite escolher os melhores indicadores do ponto de vista conceitual, pois é necessário ater-se às informações disponíveis na base de dados (GAIGER, 2007, p. 66).

Segundo Gaiger (2007), as variáveis que compõem o coeficiente de Alto Solidarismo são:

\section{i. Coletivização da produção e do trabalho;}

ii. Decisões coletivas tomadas pelo conjunto de sócios;

iii. Gestão transparente e fiscalizada pelos sócios;

iv. Participação cotidiana na gestão do empreendimento;

v. Matéria-prima ou insumos principais oriundos de outros EES;

vi. Comercialização Solidária e Preocupação com os Consumidores;

vii. Participação social e comunitária, além de Participação em Movimentos Sociais;

viii. Articulação em redes econômicas ou políticas solidárias;

ix. Ações de preservação do meio ambiente.

Em complemento a análise do Alto Solidarismo, as variáveis que compõem o coeficiente de Alto Empreendedorismo são:

i. Recursos iniciais de propriedade do empreendimento;

ii. Sede, equipamentos e espaço de comercialização próprio;

iii. Penetração ampla no mercado;

iv. Estratégia e facilidade de comercialização;

v. Capacidade de obtenção de crédito;

vi. Autossuficiência econômica e financeira;

vii. Remuneração e vínculo regular dos trabalhadores;

viii. Investimentos na formação de recursos humanos;

ix. Férias ou descanso semanal para os sócios que trabalham no EES.

Para Gaiger (2007), os indicadores de alto empreendedorismo causaram preocupação. Quase a metade dos EES não preenche nenhum indicador e um terço atende apenas a um indicador. Somente $5 \%$ atendem a três indicadores ou mais. No tocante ao alto solidarismo, o desempenho global foi superior: apenas $15 \%$ não pontuam em nenhum indicador; $31,8 \%$ pontuam em 3 indicadores ou mais; 5,3\%, em 5 indicadores ou mais (contra apenas $0,4 \%$ no alto empreendedorismo). 


\section{Os coeficientes como indicativos da sobrevivência dos EES}

Kuyven e Kappes (2013) utilizaram-se dos coeficientes para avaliar os fatores que influenciam na sobrevivência dos EES, sobrevivência esta entendida como a presença de um EES em ambos os Mapeamentos. Para isso, foi feito um recorte na base de dados do Primeiro Mapeamento, analisando apenas a região Sul do país, pois o Segundo Mapeamento desta região revisitou 95\% dos EES registrados no Primeiro Mapeamento, conferindo, assim, um alto grau de confiança na sentença de sobrevivência ou não dos EES ao longo do tempo. Nas outras regiões do país, o grau de revisitação foi inferior e, por isso, não foram considerados na análise. Além disso, analisaram-se apenas os dados da etapa de 2005 do Primeiro Mapeamento, descartando os dados da etapa complementar de 2007, pois estes não foram analisados por Gaiger (2007).

O recorte regional e por etapa do Primeiro Mapeamento registrou um total de 2.592 EES, desses, 46,3\% constam no Segundo. Tendo este valor como referência, Kuyven e Kappes (2013) analisaram cada componente dos Coeficientes, verificando se os EES que pontuam em uma dada característica têm um percentual de sobrevivência maior ou menor que os 46,3\%. Assim, por exemplo, no primeiro indicador do Coeficiente de Baixo Solidarismo (não indicou nenhuma forma de atividade coletiva), 27,8\% dos EES que o indicaram sobreviveram, enquanto 46,6\% dos EES que não o indicaram sobreviveram.

No coeficiente de Baixo Solidarismo, os indicadores que se destacam são: Não indicou nenhuma forma de atividade coletiva (27,8\% dos EES que pontuaram sobreviveram); Inexistência de assembleia ou reunião do coletivo de sócios (35,3\%); Inexistência de mecanismos de participação (35\%). Isso indica que estes são os indicadores relevantes do Coeficiente de Baixo Solidarismo no que se refere à sobrevivência dos EES. Uma baixa pontuação nestes tende a resultar em um grau de sobrevivência acima da média (que é de 46,3\%). Um indicador apresentou-se ao contrário do esperado pela teoria: os EES que possuem trabalhadores não sócios têm um grau de sobrevivência de 55,8\%, portanto acima da média.

No Coeficiente de Baixo Empreendedorismo, os destaques são: Insumos, matérias-primas ou recursos iniciais doados (39,3\%); Não conseguiu pagar as despesas do ano (37\%); Não está conseguindo remunerar os sócios que trabalham no EES (38,8\%). Já no Coeficiente de Alto Solidarismo, os indicadores que resultam em um grau de sobrevivência acima da média são: Decisões coletivas tomadas pelo conjunto de sócios (54,7\%); Gestão transparente e fiscalizada pelos sócios (52,7\%); Matéria-prima ou insumos principais oriundos de outros EES (53,7\%). Por fim, no Coeficiente de Alto Empreendedorismo, os destaques são: Recursos iniciais de propriedade do empreendimento (58,7\%); Capacidade de obtenção de crédito (65,4\%); Remuneração e vínculo regular dos trabalhadores (54,8\%); Investimentos na formação de recursos humanos (52,6\%); Penetração ampla no mercado (52,6\%).

Apesar dos resultados relevantes, a análise feita por Kuyven e Kappes (2013) baseia-se somente em uma análise de estatística descritiva. O presente trabalho visa aprimorar a abordagem dessa questão, utilizando um modelo Logit para verificar a influência dos coeficientes na sobrevivência dos EES.

\section{O modelo proposto}

Nos problemas estatísticos, as respostas podem ser analisadas, em geral, a partir de duas formas: quantitativa e qualitativa. No caso das primeiras, as respostas podem ser expressas por variáveis passíveis de mensuração, na maioria das vezes, em uma escala racional e com valores reais (WOOLDRIDGE, 2000). O segundo caso, as respostas qualitativas, podem ser expressas por variáveis categóricas, em uma escala que pode ser tanto nominal quanto ordinal. Os modelos Logit estão nesse segundo grupo. De acordo com Green (1990), esses modelos fazem parte de uma função de distribuição logística acumulada que possui a seguinte forma:

$$
P_{i}=\frac{1}{1+e^{-Z_{i}}}=\frac{e^{Z}}{1+e^{Z}}
$$

Em que é a probabilidade de um determinado evento (digamos, X), acontecer; e Z é uma função qualquer que representa os fatores que influenciam na ocorrência de X. Podemos escrever (1 - ), ou seja, a probabilidade de que não ocorra $\mathrm{X}$, da seguinte maneira:

$$
1-P_{i}=\frac{1}{1+e^{-Z_{i}}}
$$


Portanto:

$$
\frac{P_{i}}{1-P_{i}}=\frac{1+e^{Z_{i}}}{1+e^{-Z_{i}}}=e^{Z_{i}}
$$

Em que $\mathrm{P}_{\mathrm{i}} / 1-\mathrm{P}_{\mathrm{i}}$ é a razão de chances em favor de que o evento X ocorra. Se tirarmos o logaritmo da equação acima, teremos:

$$
L_{i}=\ln \left(\frac{P_{i}}{1-P_{i}}\right)=Z_{i}=\beta_{1}+\beta_{2} X_{i}
$$

Esta equação, por ser linear, pode ser estimada pelos métodos convencionais de Mínimos Quadrados Ordinários (MQO), Mínimos Quadrados Generalizados (MQG) ou Máxima Verossimilhança. Neste trabalho, as estimativas dos parâmetros serão feitas por Máxima Verossimilhança.

Quanto aos dados que serão analisados, seguiremos a metodologia empregada por Gaiger (2007) e Kappes e Kuyven (2013), trabalhando somente com os EES da Região Sul que foram mapeados na fase de 2005.

O primeiro modelo a ser estimado é, formalmente:

$$
\mathrm{I}_{\mathrm{MAP}}=\mathrm{C}+\beta_{1} \text { Coef_BS }+\beta_{2} \operatorname{Coef} f_{-} B E+\beta_{3} \operatorname{Coef} \_A S+\beta_{4} \operatorname{Coef} \_A E
$$

Em que BS, BE, AS e AE são os coeficientes de Baixo Solidarismo, Baixo Empreendedorismo, Alto Solidarismo e Alto Empreendedorismo, respectivamente; e C é a constante. Esta foi incluída na regressão porque a estatística LR, que aponta para a significância conjunta dos regressores, só pode ser calculada quando há uma constante. A Tabela 1, a seguir, apresenta os resultados da regressão.

A estatística LR do modelo, que tem a mesma função do teste F no contexto de uma estimação de MQO, aponta para a significância estatística de todos os coeficientes em seu conjunto.

Quanto à interpretação dos coeficientes, tem-se que cada valor corresponde ao aumento no logaritmo das chances dado o aumento em uma unidade da variável independente. Por exemplo, o coeficiente de Alto Empreendedorismo é de 0,13 . Portanto, o aumento de um ponto neste indicador aumenta o logaritmo das chances de sobrevivência dos EES em 0,13. Um resultado surpreendente é o sinal do coeficiente de Baixo Solidarismo. Espera-se que as práticas solidárias tornem os EES mais aptos a sobreviver, mas o resultado mostra que aumentos no coeficiente de baixo solidarismo aumentam a chance de sobrevivência dos EES.

Tabela 1 - Resultados da primeira regressão

\begin{tabular}{lccc}
\hline Variável & Coeficiente & Erro-Padrão & P-valor \\
\hline C & $-0,527$ & 0,147 & 0,0003 \\
COEF_BS & 0,076 & 0,032 & 0,0155 \\
COEF_BE & $-0,109$ & 0,044 & 0,0126 \\
COEF_AS & 0,088 & 0,033 & 0,0067 \\
COEF_AE & 0,130 & 0,038 & 0,0007 \\
Estatística LR & 35,51 & & \\
P-valor (LR) & 0,00 & & \\
\hline
\end{tabular}

Fonte: SIES/Base atualizada 2013; cálculos elaborados pelos autores com o software Stata

Outra forma de interpretar esses resultados é utilizando o que Kohler e Kreuter (2012) chamam de Efeito Marginal Médio. Esse cálculo informa, em termos percentuais, qual o efeito do aumento em uma unidade de uma variável independente na variável dependente. A Tabela 2 apresenta os efeitos marginais médios da regressão anterior. 
Tabela 2 - Efeitos marginais médios da primeira regressão

\begin{tabular}{lccc}
\hline Variável & $\mathbf{d y} / \mathbf{d x}$ & Erro-Padrão & P-valor \\
Coef_BS & 0,0190404 & 0,00786 & 0,015 \\
Coef_BE & $-0,0271809$ & 0,0109 & 0,013 \\
Coef_AS & 0,0219785 & 0,0081 & 0,007 \\
Coef_AE & 0,0324772 & 0,00954 & 0,001 \\
\hline
\end{tabular}

Fonte: SIES/Base atualizada 2013; cálculos elaborados pelos autores com o software Stata

A interpretação do coeficiente de Baixo Solidarismo é a de que o aumento em uma unidade nesta variável aumenta em 1,9\% a chance de sobrevivência de um EES. O sinal negativo no coeficiente de Baixo Empreendedorismo significa que aumentos nessa variável reduzem a sobrevivência dos EES. O passo seguinte em nosso exercício econométrico foi estimar uma regressão em que os coeficientes são desagregados em suas partes componentes, ou seja, cada um dos seus 9 indicadores, ficando assim com 36 variáveis. Os resultados são apresentados na Tabela 3.

Tabela 3 - Resultados da segunda regressão

\begin{tabular}{|c|c|c|c|c|}
\hline Variável & Descrição & Coeficiente & Erro-Padrão & P-valor \\
\hline C & Constante & $-0,283$ & 0,216 & 0,190 \\
\hline AE1 & $\begin{array}{l}\text { Recursos à montante (insumos, matérias-primas e recursos } \\
\text { iniciais) de propriedade do empreendimento }\end{array}$ & 0,209 & 0,183 & 0,253 \\
\hline AE2 & Sede, equipamentos e espaço de comercialização próprios & 0,200 & 0,148 & 0,176 \\
\hline AE3 & Penetração ampla no mercado & 0,120 & 0,141 & 0,396 \\
\hline AE4 & Estratégia e facilidade de comercialização & 0,000 & 0,101 & 1,000 \\
\hline AE5 & Capacidade de obtenção de crédito e investimento & 0,738 & 0,196 & 0,000 \\
\hline AE6 & Auto-suficiência econômica e financeira & $-0,048$ & 0,110 & 0,667 \\
\hline AE7 & Remuneração e vínculo regular dos trabalhadores & 0,187 & 0,134 & 0,164 \\
\hline AE8 & Investimentos na formação dos recursos humanos & 0,082 & 0,211 & 0,697 \\
\hline AE9 & $\begin{array}{l}\text { Férias ou descanso semanal para os sócios que trabalham no } \\
\text { empreendimento }\end{array}$ & $-0,190$ & 0,153 & 0,216 \\
\hline AS1 & Coletivização da produção e do trabalho & $-0,139$ & 0,125 & 0,267 \\
\hline AS2 & Decisões coletivas tomadas pelo conjunto de sócios & 0,330 & 0,109 & 0,002 \\
\hline AS3 & Gestão transparente e fiscalizada pelos sócios & 0,138 & 0,101 & 0,174 \\
\hline AS4 & Participação cotidiana na gestão do empreendimento & $-0,445$ & 0,149 & 0,003 \\
\hline AS5 & $\begin{array}{c}\text { Matéria-prima ou insumos principais de empreendimentos } \\
\text { solidários }\end{array}$ & 0,223 & 0,128 & 0,081 \\
\hline AS6 & Comercialização solidária & $-0,072$ & 0,140 & 0,607 \\
\hline
\end{tabular}


Tabela 3 - Conclusão...

\begin{tabular}{|c|c|c|c|c|}
\hline Variável & Descrição & Coeficiente & Erro-Padrão & P-valor \\
\hline AS7 & Participação social e comunitária & 0,226 & 0,181 & 0,211 \\
\hline AS8 & Articulação em redes econômicas ou políticas solidárias & $-0,211$ & 0,167 & 0,206 \\
\hline AS9 & Ações de preservação do ambiente natural & 0,136 & 0,089 & 0,125 \\
\hline BE1 & insumos, matérias-primas e recursos iniciais doados & $-0,070$ & 0,206 & 0,733 \\
\hline BE2 & sede e equipamentos cedidos ou emprestados & $-0,127$ & 0,113 & 0,259 \\
\hline BE3 & Produção destinada unicamente ao autoconsumo & 0,177 & 0,164 & 0,280 \\
\hline BE4 & Despreparo para a prática de comercialização & 0,293 & 0,166 & 0,077 \\
\hline BE5 & Não conseguiu pagar as despesas do ano & $-0,430$ & 0,141 & 0,002 \\
\hline BE6 & $\begin{array}{l}\text { Não está conseguindo remunerar os sócios que trabalham no } \\
\text { EES }\end{array}$ & $-0,197$ & 0,158 & 0,213 \\
\hline BE7 & Não existem benefícios para os sócios trabalhadores & $-0,184$ & 0,092 & 0,044 \\
\hline BE8 & Trabalhadores não sócios em caráter permanente, na produção & 0,212 & 0,217 & 0,328 \\
\hline BE9 & Inexistência de tratamento de resíduos gerados pelo EES & $-0,398$ & 0,388 & 0,305 \\
\hline BS1 & Não indicou nenhuma forma de atividade coletiva & $-1,079$ & 0,389 & 0,006 \\
\hline BS2 & Inexistência de assembleia ou reunião do coletivo de sócios & $-0,233$ & 0,239 & 0,329 \\
\hline BS3 & Ausência de outros órgãos diretivos de natureza democrática & $-0,156$ & 0,119 & 0,191 \\
\hline BS4 & Inexistência de mecanismos de participação & $-0,404$ & 0,241 & 0,094 \\
\hline BS5 & Existência de trabalhadores não sócios & 0,141 & 0,209 & 0,500 \\
\hline BS6 & Ausência de participação em rede ou fórum de articulação & $-0,161$ & 0,090 & 0,073 \\
\hline BS7 & Ausência de participação em movimento sociais e populares & 0,172 & 0,132 & 0,192 \\
\hline BS8 & $\begin{array}{c}\text { Ausência de realização ou participação em ação social ou } \\
\text { comunitária }\end{array}$ & 0,190 & 0,130 & 0,145 \\
\hline BS9 & $\begin{array}{c}\text { Inexistência de preocupação com a qualidade de vida dos } \\
\text { consumidores }\end{array}$ & 0,176 & 0,100 & 0,077 \\
\hline \multicolumn{5}{|l|}{ Estatística } \\
\hline LR & & 132,421 & & \\
\hline P-valor (LR) & & 0,000 & & \\
\hline
\end{tabular}

Fonte: SIES/Base atualizada 2013; cálculos elaborados pelos autores com o software Stata

A estatística LR, mais uma vez, aponta para a significância estatística de todos os coeficientes em seu conjunto. Entretanto, muitos deles, individualmente, não são estatisticamente diferentes de zero ${ }^{1}$, como pode ser verificado pelo p-valor de cada um deles. Por conta disso, foi estimado um terceiro modelo, que usa apenas as variáveis cujos coeficientes são estatisticamente significantes em termos individuais. O modelo alternativo é o seguinte:

1 Levando-se em consideração o valor crítico de $5 \%$. 


$$
\mathrm{II}_{\mathrm{MAP}}=\mathrm{c}+\beta_{1} A E 5+\beta_{2} A S 2+\beta_{3} A S 4+\beta_{4} B E 5++\beta_{5} B E 7+\beta_{6} B S 1
$$

Os resultados da regressão são apresentados na Tabela 4.

Tabela 4 - Resultados da terceira regressão

\begin{tabular}{lccc}
\hline Variável & Coeficiente & Erro-Padrão & P-valor \\
C & $-0,069$ & 0,064 & 0,280 \\
AE5 & 0,777 & 0,191 & 0,000 \\
AS2 & 0,429 & 0,096 & 0,000 \\
AS4 & $-0,356$ & 0,106 & 0,001 \\
BE5 & $-0,440$ & 0,136 & 0,001 \\
BE7 & $-0,214$ & 0,081 & 0,008 \\
BS1 & $-0,879$ & 0,380 & 0,021 \\
Estatística LR & 74,514 & & \\
P-valor (LR) & 0,000 & & \\
\hline
\end{tabular}

Fonte: SIES/Base atualizada 2013; cálculos elaborados pelos autores com o software Stata

Esses resultados serão interpretados com os Efeitos Marginais Médios, apresentados na Tabela 5. A capacidade de obtenção de crédito eleve a chance de sobrevivência de um EES entre o primeiro e o segundo mapeamento em $19 \%$. A tomada de decisões de forma coletiva, por sua vez, eleva em 10,7\%. A participação cotidiana na gestão do EES, surpreendentemente, reduz as chances de sobrevivência em 8,7\%. A incapacidade de pagar as despesas do ano reduz em $10,7 \%$. A inexistência de benefícios para os sócios trabalhadores reduz a sobrevivência em 5,3\%. Não ter nenhuma atividade econômica coletiva, por fim, reduz a sobrevivência em $20 \%$.

Tabela 5 - Efeitos marginais médios da Equação (6)

\begin{tabular}{|c|c|c|c|c|}
\hline Variável & Descrição & dy/dx & Erro-Padrão & P-valor \\
\hline ae5 & Capacidade de obtenção de crédito. & 0,190 & 0,044 & 0,000 \\
\hline as2 & Decisões coletivas tomadas pelo conjunto de sócios. & 0,107 & 0,024 & 0,000 \\
\hline as 4 & $\begin{array}{l}\text { Participação cotidiana na gestão do } \\
\text { empreendimento. }\end{array}$ & $-0,087$ & 0,026 & 0,001 \\
\hline be5 & Não conseguiu pagar as despesas do ano. & $-0,107$ & 0,032 & 0,001 \\
\hline be7 & Não existem benefícios para os sócios trabalhadores. & $-0,053$ & 0,020 & 0,008 \\
\hline bs1 & Não indicou nenhuma forma de atividade coletiva. & $-0,200$ & 0,075 & 0,007 \\
\hline
\end{tabular}

Fonte: SIES/Base atualizada 2013; cálculos elaborados pelos autores com o software Stata.

\section{Análise dos resultados}

Analisando primeiro as questões econômicas, tanto de alto quanto de baixo empreendedorismo, verificam-se resultados pouco surpreendentes. A capacidade de obtenção de crédito, que aumentou em 19\% as chances de sobrevivência dos EES que possuíam essa característica, aponta para o papel importante das políticas voltadas para a ampliação do acesso ao crédito. Esse foi o coeficiente que mais aumentou a chance de sobrevivência dos EES, o que sugere que políticas públicas voltadas ao crédito são importantes para a Economia Solidária. Cabe destacar, ainda, que a mera formulação desse coeficiente, e o fato de que ele aumenta as chances de sobrevivência, indica que muitos EES não têm acesso a crédito, o que indica, entre outras coisas, o grau de informalidade dos empreendimentos, a 
ausência de registros contábeis capazes de garantir acesso a crédito bancário etc.

Os coeficientes de baixo empreendedorismo estatisticamente significativos foram a incapacidade de pagar as despesas do ano e a inexistência de benefícios (como vale alimentação ou vale transporte) aos sócios que trabalham no empreendimento, que reduzem as chances de sobrevivência em, respectivamente, $10,7 \%$ e $5,3 \%$. Novamente, a mera formulação desses coeficientes e sua significância estatística mostram a fragilidade que muitos EES se encontram. Pode-se dizer que, em geral, os EES possuem pouco acesso a crédito, não pagam todas as despesas do ano e não pagam benefícios aos seus trabalhadores. Além de indicar informalidade, isso aponta para a pouca capacidade de geração de renda de muitos EES, e também sua desorganização econômico-financeira. Em termos de políticas públicas, cursos de capacitação aos gestores dos EES pode ser um importante instrumento para melhorar a capacidade de sobrevivência dos empreendimentos.

Passando à análise das questões solidárias, temos que a tomada de decisões realizada pelo conjunto dos sócios aumenta em 10,7\% a sobrevivência dos EES. Isso reforça um dos pilares da Economia Solidária, que é a participação de todos e todas nas decisões do EES. Há limites, porém, no quanto a gestão colaborativa melhora a sobrevivência dos EES. A participação cotidiana dos sócios na gestão do empreendimento reduz as chances de sobrevivência em $8,7 \%$. Isso pode indicar, entre outras coisas, que a participação de muitas pessoas na gestão cotidiana pode gerar atritos, falhas de comunicação ou lentidão na tomada de decisões. Além disso, pode indicar que sócios (as) com pouca capacidade gerencial, ao se envolverem na gestão, acabam por atrapalhar. Por fim, a inexistência de atividades coletivas reduz as chances de sobrevivência em $20 \%$. Tomados em conjunto, esses resultados indicam que a existência de atividades coletivas e a tomada de decisões coletivas melhoram os resultados dos EES, mas que essa instância coletiva, se for levada muito longe, acaba por reduzir a sobrevivência dos EES.

\section{Considerações Finais}

Os EES possuem uma racionalidade produtiva distinta, calcada em relações de solidarismo. Entretanto, os empreendimentos não devem deixar de lado a dimensão da eficiência econômica, sob o custo de não se viabilizarem financeiramente. Além disso, as dificuldades econômicas estão relacionadas a diversos outros problemas como o alto nível de informalidade dos empreendimentos (BOSI, 2008), o aprofundamento de diversas formas de precarização nas relações de trabalho (CACCIAMALI, CORTÉS, 2010), alto índice de falências (BONIN, ET. AL., 1993), entre outros problemas.

A conjugação dessas duas dimensões, solidária e econômica, foi o que motivou Gaiger (2007) a criar os coeficientes de solidarismo e empreendedorismo, com o objetivo de analisar as relações entre essas duas dimensões. Kuyven e Kappes (2013) utilizaram esses coeficientes para analisar a sobrevivência dos EES entre o primeiro e o segundo Mapeamentos Nacionais. Neste trabalho, os coeficientes utilizados pelos autores citados foram estudados em um modelo Logit. Após descartar as variáveis sem significância estatística, restou um modelo que aponta para a importância da capacidade de obtenção de crédito e das decisões tomadas pelo conjunto dos sócios no sentido de elevar a sobrevivência dos EES, enquanto a participação cotidiana na gestão do empreendimento, a incapacidade de pagar as despesas do ano, a inexistência de benefícios para os sócios trabalhadores e a ausência de atividades coletivas reduzem a probabilidade de que tal sobrevivência ocorra. A significância estatística de variáveis que contemplam tanto o lado econômico quanto o solidário permite concluir que ambas as dimensões, solidária e empreendedora, têm impactos na longevidade dos EES.

\section{Referências}

BALTAGI, B. H. Econometrics. 3. ed. Berlin: Springer, 2002.

BONIN, J. P.; ET. AL. Theoretical and Empirical Studies of Producer Cooperatives: Will Ever the Twain Meet? Journal of Economic Literature, v. 31, n. 3, p. 1290-1320, Sept. 1993.

BOSI, A. P. A organização capitalista do trabalho "informal": o caso dos catadores de recicláveis. Revista Brasileira de Ciências Sociais. [online]. 2008, vol. 23, n.67, pp. 101-116.

CACCIAMALI, M. C. e CORTÉS, D. L. R. Cooperativas de trabalho associado, instrumentos de precarização ou de resgate de relações de trabalho justas? Um estudo do caso do Brasil - Colômbia a luz do conceito de trabalho decente. Pesquisa \& Debate, v. 21, n.2 (38), p. 307-337, 2010. 
CATTANi, A. D. (Org.). A outra economia. Porto Alegre: Veraz, 2003.

CARPRI, J. La economía social em um mundo em transformación. Revista Ciriec-España, n.25, p. 83-115. 1997.

FRANÇA FILHO, G. C. Esclarecendo terminologias: as noções de terceiro setor, economia social, Economia Solidária e economia popular em perspectiva. Revista de Desenvolvimento Econômico, v. 4, n. 7, jan. 2002.

GAIGER, L. Eficiencia sistêmica. In: Antônio Cattani (org.), La otra economía. Buenos Aires: Altamira, 213-220. 2004.

GAIGER, L. A outra racionalidade da economia solidária. Conclusões do Primeiro Mapeamento Nacional no Brasil. Revista Crítica de Ciências Sociais, Coimbra, Centro de Estudos Sociais, n.79, p. 57-77, 2007.

GAIGER, L. Empreendimento Econômico Solidário. In: GAIGER, Luiz et al. (Org.) Dicionário internacional da outra economia. Coimbra: Almedina, 2009.

GREEN, W. Econometrics analysis. New York: Macmillan Publishing Company, 1990. 1178 p.

GUJARATI, D. Econometrics. 2. ed. Boston: McGraw-Hill, 1999.

KUYVEN, P. S; KAPPES, S. A. Relação entre o grau de solidarismo e o índice de sobrevivência de empreendimentos econômicos solidários na região sul do Brasil. VIII Congresso Internacional Rulescoop. São Leopoldo, 2013.

KOHLER, U.; KREUTER, F. Data Analysis Using Stata. College Station: Stata Press, 2012.

LAVILLE, J; GAIGER, L. Economia solidária. In: GAIGER, Luiz et al. (Org.) Dicionário internacional da outra economia. Coimbra: Almedina, 2009.

NYSSENS, M. Économie populaire au Sud, économie sociale au Nord: dês germes d'économie solidaire? In: SAUVAGE, P., Réconcilier l'économique et Le social, Paris: OCDE. 1996.

RAZETO, L. Las empresas alternativas. Montevideo: Editorial Nordan-Comunidad. 1990.

SCHIMDT, C. A economia solidária: panacéia do capitalismo pós-moderno ou um caminho para o socialismo. Textos para a Discussão - NEA/ITCP. Faculdade de Ciências Econômicas UFRGS. Porto Alegre: 2010. (mimeo).

SCHIOCHET, V.; SILVA, R. M. A. Economia Solidária no Plano Brasil Sem Miséria: A Construção de Estratégias Emancipatórias para a Superação da Pobreza Extrema. In: IPEA. Mercado de Trabalho: Conjuntura e Análise, n. 18 , p. 69-82, fev. 2013.

SINGER, P. Economia Solidária: Entrevista com Paul Singer. Estudos Avançados, v. 22, n. 62, p. 289-314, 2008.

SINGER, P. Economia Solidária: um modo de produção e distribuição. In: SINGER, P. e SOUZA, A. (Org.) A Economia Solidária no Brasil. São Paulo: Contexto, 2003.

VERANO, L. Economia Solidária: uma alternativa ao neoliberalismo. Santa Maria: CESMA. 2001.

WOOLDRIDGE, Jeffrey M. Introductory Econometrics: a Modern Approach. 2000, South-Western College Publishing, a division of Thomson Learning. 